JOURNAL

of Health Inequalities

\title{
How has Norway beaten the COVID-19 pandemic?
}

\author{
- I remember the meeting in February last year at ECDC in Sweden - we were looking at the figures, \\ and some argued that "it's unstoppable". Others pointed to China, and we were saying maybe yes. \\ Fast lockdown, movement restrictions, mass tests, precise contact tracking and reporting. But is it possible \\ to implement these measures in a Western democracy? \\ Frode Forland from the Institute of Public Health tells us how Norway managed to overcome the pandemic.
}

Norway is seen as a model in the fight against COVID-19. In 15 months, just 789 people died from the coronavirus; in Poland, only on November 7, 2020, 1249 died. How did you do it?

I think there are maybe three main reasons for that. The first is what I would call the rapid lockdown that was done. We saw this coming in January and February and the beginning of March. And then, around the tenth of March, we saw that the virus was suddenly spreading through society, which we could not trace back to travel. That was when we understood it was starting to spread within the country without us knowing where. And that was when the decision was taken by the government together with the Directorate of Health and the Public Health Institute that we should have a proper lockdown, which was implemented on the $12^{\text {th }}$ of March. That had a surprisingly great effect, which actually happened pretty fast. So, within three weeks, we saw the curve turning, and it was turning fast, and again to a level that we could cope with during April and May, and to a gradual reopening towards summer last year. The second issue was that we have a system in Norway regarding infectious disease control connected to the municipality level of the administration of the country. In Norway, there are three hundred and fifty-six municipalities. And in each municipality there is an infectious disease doctor responsible for contact tracing, quarantining, and for isolation and testing when there is a local outbreak. The idea of having this local responsibility has been part of the success factor. And it also means that in every municipality what we call a contact tracing team has been established. Hence, a total of 2500 people have been registered as contact tracers, and have been ready to do so every time there's a local outbreak, meaning we've been able to shut down all the minor outbreaks that have appeared almost all over the country. There are only 10 municipalities left which have had no cases until now. Every day and every week, we receive an overview, and we are supporting and guiding each municipality where there is a need for extra measures in addition to the national measures, which are always at the core of our actions. So that's the second item, I would say. The third has been related to the border control; we've had rather strict measures for people travelling to Norway. Travelers are also required to have a negative test before they go, as well as having to test at the border when they come to the harbor or the airport, and the obligation of going into 10 days of quarantine for everybody.

You did not mention the low population density the demographics must have helped you?

Certainly - everything is much easier when there are 15 inhabitants per square kilometer, rather than 382 people as in the case of India. And we've seen that most of the outbreaks or the difficult outbreaks have been in Oslo. But at the same time, the second and the third largest towns have not been very hard hit, and they've been able to control the outbreaks with local measures, like in Bergen and Trondheim.

Who were the "brains" of the implemented strategy: politicians, epidemiologists, infectious disease doctors?

Our strategy was developed during the first weeks partly by the Public Health Institute and partly by the Directorate of Health, which is like an implementing body for government policies. The overall picture is that we (the Public Health Institute) are like the knowledge bank, the knowledge base. Then the legal measures are handled mainly by the Directorate of Health at a national level and at the municipal level, by the municipal doctors, and by the municipal authorities that are the locally elected part of the democracy. From the $12^{\text {th }}$ of March the strategy against COVID-19 became a government issue, and the Minister of Health and the Minister of Preparedness took over the responsibility on behalf of the Prime Minister. So there has been whole government involvement from the point when we understood that this is no longer just a health issue, but an issue concerning the whole of society - it affects industry, travel, production of food, schools, kindergartens, culture, and almost everything else. 
How did society adapt to the main first measures?

With understanding, but also with insecurity and accompanying uncertainty. Goods were disappearing from the shelves of shops. However, it was not only through fear that people decided to accept the restrictions, but also their trust in the government, which is very high in Norway. And that is a very important factor when it comes to understanding how this can work in a society with an open democracy, in which you are free to criticize the government as well. There has been no serious opposition to the measures but an open debate about measures that should be taken. In the end, even the opposition in the parliament supported the strategy chosen by the cabinet and the government. So, this trust in society at both the national level and the local regional level is also a part of the success story.

What you've just said largely explains why Poland it at the bottom end. There was fear for life, but there was also very little trust in the authorities, and after the presidential election, there was also a lack of understanding of the actions taken. We heard that the virus was in retreat, we saw politicians wearing masks upside down...

There is a difference between adapting to danger and getting used to fear, as we have all experienced, and downplaying the threat and ignorance. You mentioned vaccines, which was the last success factor. We are able now to obtain vaccines very fast, which is something we did not expect a year ago. This has been a surprisingly big success story when it comes to the use of research and technology development during a pandemic, which has never happened before. That's something that benefits the whole world and makes it clear that this is still an epidemic or a pandemic of inequity around the world, seeing the worst hit countries like India, Pakistan, and Bangladesh not having access to the same numbers of vaccines that we have in the West and in Europe.

Let's go back to March 2020 - how would you rate the baseline situation when the pandemic broke out? I mean the preparation of health care, especially in the field of infectious diseases. In Poland there was a lack of specialists and equipment, and frequently changing recommendations regarding behavior during the pandemic.

I would say there were a lot of plans in Norway, and many of them were not fully implemented, not fully tested or practiced. There was a lack of equipment like masks, ventilators, ICU beds, even though after the last pandemic from the flu in 2009-2010 plans were made to scale up and have the ability to really master any new pandemic. But it wasn't really put into practice related to buying equipment. And where should we get it from? Suddenly, the whole world wanted it at the same time. So, then there was a bit of flexibility here because the Norwegian minister of health knew somebody in China who somehow was connected to a factory that produced face masks. As you can see, these were highly improvised measures taken in the first place, with an airplane flying to China to buy masks. But still, I think there were also a lot of things to criticize with the Norwegian level of preparedness. And there has been a big report written by a commission that has gone through the whole system in Norway. It's 450 pages long. The main conclusion is that the government was not prepared, but they were very flexible and able to cope, even in a situation of uncertainty and lack of preparedness. The report also concludes that the people's trust in the government has been a huge success factor.

I think that most of the world was unprepared, except Asia..

Maybe they were not fully prepared either. But in eastern Asian countries there has been a kind of understanding, at least of the use of face masks, that has been very different from other parts of the world. In Norway we were actually waiting for a very long time before we were given advice to use masks in places other than health services, because we were really waiting for evidence. And we still claim that there is no good evidence for the use of face masks outside, for instance. You need to mask so many people before you can prevent one case that it's not a cost-effective measure. We were calculating during the summer that we needed to mask 200,000 people to prevent one case with the level of infection spread that was in Norway last summer. Right now, it's an obligation to use masks on buses and trains, in shops and other places where you cannot keep a distance of one meter.

Were there any bizarre situations such as sewing of masks by doctors, wearing ski googles?

I've not seen that really.

What about outbreaks in hospitals, teams of doctors in quarantine?

Yes, we had some of them in the beginning. This is also an interesting development because of how the epidemic came to Norway - do you know about that?

By a woman returning from China?

It was actually just the first case, but the main wave of the first infections came from people who had been skiing in winter resorts in the Alps in Austria and Italy.

\section{Similar to Sweden...}

Yes. The epidemic had been brought back by highincome people like dentists and doctors, who brought it back directly to the hospitals. And a lot of people ended up being quarantined from some of the bigger hospitals in Oslo, for instance. Later it spread to society. In the beginning, we didn't know how many people were infected because the tests were not fully developed; we 
had to develop them ourselves at our institute. During the first phase of the pandemic, I think that we were able to identify maybe $10 \%$ of the cases. Now we capture $60-70 \%$ of the cases with the testing regime we have.

Many of the victims of COVID in Norway, as in many other countries, were residents of communal old people's homes. Do COVID and poverty go hand in hand?

Yes and no, because you just heard my argument people who were on holiday brought it back from the ski resorts to the nursing homes. In Norway, staying at a nursing home doesn't mean that you are poor. It's like a service for everybody, regulated by need, not poverty.

But when I looked at the statistics, I had the impression that more people died in communal homes than in commercial ones?

No, that's not really anything that we can say as a general rule. Around $50-60 \%$ of the deaths have been in nursing homes, the same as in Sweden. And in Sweden as well, they've been trying to see if there were more victims in commercial or in communal and municipal homes, and they have not found any difference. In the beginning, the opposite trend was seen to what you are saying. So, I think the problem of the nursing homes is that they are just reflecting the spread within society. And, of course, in a nursing home, that's where the people are closest to death and have the highest risk of dying from COVID-19. In that sense, it's kind of natural, and it's very difficult to really stop it at the institutional border.

In retrospect, do you see any mistakes that could have been avoided?

Of course, and there is a lot to learn still. Closing schools and kindergartens during the first lockdown might have been an overreaction. We didn't have enough evidence and we've seen from the examples of Finland and Sweden that it's possible and probably better to keep schools open. All you need to do is just implement good infectious disease control measures like a traffic light system with red, yellow, and green levels. That's something we learned from Sweden.

And what about colleges and universities?

That's different - there is more logic in keeping young people and students at home because they can deal with the whole online learning idea.

It was also a big dilemma in Poland. After the first lockdown and upon reopening schools we saw a COVID death spike, and many people started to blame children....

We've seen that the new English variants are spreading more among children. And it has been a challenge to deal with it in the last three or four months.
Let's talk about other Scandinavian countries - Finland has also introduced a lockdown, and the death toll is relatively small (964). On the other hand, we have Sweden, which chose its own path - do you remember your first thoughts when you heard about Tegnell's strategy?

It's not really something I heard about, it's something I've been close to in discussions. We've been having meetings with the other Nordic countries, including Sweden, from the beginning of the pandemic every second week. I talk on the phone with colleagues from Sweden, Finland, Denmark, and Iceland on a regular basis. In the beginning there was a kind of uncertainty: what is the right strategy? I remember the meeting in February last year at ECDC in Sweden - we were looking at the figures, and some were thinking it's possible to stop this; some were saying maybe not. We looked at what happened in China, and we saw that with the societal measures used in China, it seemed like you could stop it. That was already shown from that time. But are these measures possible to implement in a western democracy - that's one of the biggest questions that we still couldn't really answer. Then we saw that some countries were taking a more relaxed approach to see if this would just pass through the country, as happens with all influenza pandemics, and some other countries were taking stricter measures straight away. And there was no clear advice from the EU or the ECDC on what to do. It was up to each country to decide.

At any point, did you think that Norway could adopt the more relaxed method?

Actually, this was under discussion, and there were different views. I was thinking it's possible to control it by societal measures - as we have seen in province after province in China, and then it was possible to control the full-blown outbreak in Wuhan. But this was a hard decision to take, and I'm happy that the government took over the responsibility for that. It does not only affect people's health, and that's why the whole cabinet took over control, to state that we need to include everybody in understanding the consequences of this. The effect of the lockdown was surprisingly huge and rapid. And that's when we actually saw the difference developing from March and April last year until now with those countries that had a big spread of the virus in the country without knowing it in the first place. They've been struggling to get the numbers down again for the rest of the pandemic, including Poland, the Czech Republic, France, Italy, and Spain. It was the same in the UK, until they got the vaccine that they've been able to distribute among their population, but now the number of cases is dropping faster.

In Poland, the Swedish path is perceived as a successful experiment, but if we look at the numbers it 
seems more like a failure - twice the population of Norway, almost twice the population density, similar life expectancy, and 14,574 deaths from COVID-19. Could it have been much lower?

I think that the numbers speak for themselves. Sweden and Norway are countries that in many ways are very alike. We have the same welfare system, the same trust in the government. It has been interesting to see that people in Sweden still trust their government, like Norwegians do. Sweden has seen ten-fold higher numbers of deaths, hospitalized people, and people needing intensive care (ICU). It's been a dramatic difference, which has primarily been due to the three things that I mentioned earlier. When they first imposed a lockdown and societal interventions, they had stricter measures than Norway for a long period during the summer last year. That was probably beneficial for the economy of the country. In Norway we've had a lot of local variations in the measures - when there is an outbreak, we close down some municipalities for three/four/five weeks if necessary and then open them up again. And then we have been able to curb that outbreak by contact tracing, testing, and putting people in isolation and quarantine. That has been the way. Even now we are doing mass testing. When there is an outbreak in a school, for instance, we test every student maybe twice a week, to avoid putting the whole school in quarantine.

Surely you've heard of Tegnell's fan club - do you think they will be removing tattoos of his face?

I don't know, but I'm happy that I don't have that same role. I'm more of an advisor - we are sharing the power both within the institute and between the three main bodies: the Government, the Directorate of Health, and the Public Health Institute. In Sweden more power has been placed in one institution, the Public Health Authority, with Tegnell as the lead epidemiologist in the country.

In Poland, conspiracy theories that coronavirus is a product of "Big Pharma" are very popular. Do Norwegians also have a soft spot for science fiction?

There are very few conspiracy theories compared to other countries in Europe, but some of these conspiratorial terrorists gathered in a kind of illegal meetings. You might have heard of our top corona sceptic, Hans Kristian Gaarder, who denied the virus and died of COVID-19. It became a big issue in the media. Fortunately, about $90-95 \%$ of people want to be vaccinated and believe this is the only way out of the pandemic.

This is definitely more than in our country - Poles are afraid of vaccines, especially AstraZeneca. In early May, Norway stopped using AstraZeneca, and $\mathrm{J} \& \mathrm{~J}$ is offered only to volunteers - was that a good decision?

I think so. In Norway, four people after receiving the Astra Zeneca vaccine died because of severe blood clotting. With such a low risk of infection in the country that's a high number. Serious side effects were seen, especially in younger people, so we decided to take the virus vector vaccines out of the program.

It is said that AstraZeneca is like a boomerang it flies out of the vaccination program and then returns to it; the latest example is the Netherlands...

If there is a high risk of infection and a high infection level, the benefit is much greater than the harm. But in a country with a low infection rate, it doesn't really add up to the same fraction between the benefit and the harm.

So how many people are vaccinated right now in Norway?

Around 45\% have had their first dose, but a smaller number have had their second dose. The plan is to vaccinate the whole adult population by the end of July.

And what are the rules? You started with the oldest?

Yes, and we've been going down by 10 years adding the risk groups. However, now we are vaccinating a little bit differently in different parts of the country. For the younger adults between 18 and 45 years old we decided to start with a lower age group like the 18 to $25 \mathrm{~s}$, vaccinating them before those in the age group above because they practice more risky behavior. We are going now both from the lower end and upper end age groups to meet in the middle, i.e. those in their 30s. We've also had a lot of discussion about the distribution of the vaccine to make it more targeted to where weve seen the greatest spread. Recently the Ministry of Health followed our advice and decided to target more vaccines to areas of Oslo and some of the municipalities and towns around Oslo, where there has been a higher level of infection throughout the whole pandemic. That will benefit both the local population and the population as a whole, because a lot of the spread comes from the city and out to the more rural areas.

That's clever. What do you think about the whole idea of "COVID-19 passports"? Will they give us freedom or limit civil liberties?

The "corona certificates", as we call them, would cover anyone vaccinated against COVID-19 or those who have had a negative test or have recently recovered. So, in fact, they are a solution that will facilitate travel without the need to quarantine or perform additional testing in European Union countries. At the moment, together with Poland and other EU countries, we are primarily considering how to prevent falsification of such documents. I think that the work will be completed and the regulations will be implemented at the end of June.

It's funny that you mentioned counterfeits. I recently heard that "COVID passports" might be a good business... 
We've had challenges related to it. For instance, some Polish workers told us that it was easier to get a counterfeit certificate than have a test at a certain time. So, it's good to have this kind of structure for a certificate which is the same for the whole of Europe.

In Poland, more and more attention is being paid to the "health debt", which is a consequence of freezing health care for many months. To what extent has the pandemic impaired access to treatment in Norway?

I think that's an important question and an important issue. In the first phase of the pandemic, we fell behind on waiting lists in the hospitals, but during the summer months last year, when the infection rate was very low, the hospitals were able to catch up and get back to normal service levels. And actually we saw some very interesting findings when we looked at the figures of the infection rate - during the three first months, March, April, and May last year, we saw a drastic drop in all reported infections (influenza, sexually transmitted diseases, other respiratory diseases). These have been at a lower level than ever before, dropping by something like $60 \%$. We also saw that the influenza epidemic last winter dropped down to nothing. What's even more interesting, some of the major causes of death have been going down, like heart diseases, lung diseases, and some forms of cancer as well. These measures in society may also have positive effects on life expectancy, which is striking. We've seen for the first three months of this year that there has been a big drop also in the total mortality. But when we look at the death rates for the whole of 2020, we only see a significant drop in death rates from lung diseases.

We started our conversation with the factors that made Norway successful in fighting the pandemic; finally, I would like to ask you about conclusions for the future. How can we avoid a repeat of this pandemic?

It's always a matter of being prepared for something you cannot fully prepare for. Nevertheless, we can learn a lot at the systemic level of how a society can cope. It is very important to document the lessons that we are learning now, so that we are better prepared for the future. Next time it might be a disaster caused by a nuclear power plant, antimicrobial resistance, or climate change...

The interview was prepared by Zuzanna Opolska, freelance health writer and journalist. It was first published in Polish on Medonet, a leading medical website.

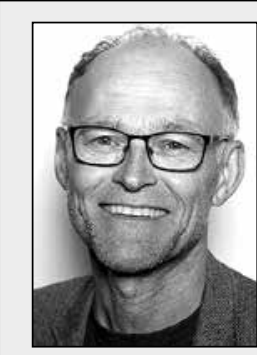

Frode Forland is the Director of Infectious Diseases and Global Health at the Norwegian Institute of Public Health and Associate Professor at the University of Tromsø, the Arctic University of Norway. As a Specialist Director of Infectious Diseases and Global Health, he is a member of the COVID-19 leadership group of the Norwegian Institute of Public Health, and has a strategic and central role in the Norwegian response to the pandemic. He has worked at the European Center for Disease Prevention and Control (ECDC) in Stockholm with development of methods for evidence-based public health in Europe, and has published widely on topics related to evidence-based medicine and global health. He represents Norway in the Advisory Forum of the ECDC, and he is a member of the Scientific Committee for the ESCAIDE conference (European Scientific Conference on Applied Infectious Disease Epidemiology). 